\title{
Domestic refrigerator with water cooled condenser - A Review
}

\author{
Rahul V Patil, Dr. G.S. Sharma* \\ Reserch Scholar, Oriental University Indor, M.P., India \\ *Dean , Engineering \& Technology, Oriental University Indor
}

\begin{abstract}
The paper reviews the possibilities of researchers in the field of performance of the domestic water cooled refrigerators and its utilization in commercial and industrial applications. Here, it is found that the performance of water cooled condenser depends on the inlet temperature, compressor pressure and condensing temperature. The recovery of waste heat from the water cooled condenser is utilised increasing the temperature of cold water. This hot water can be utilised in various domestic as well as industrial applications. The power consumption required for refrigeration can be optimised by using mathematical modelling.
\end{abstract}

Key words: Water cooled condenser, performance, mathematical modelling,

DOI: $10.7176 / \mathrm{NCS} / 10-05$

Publication date:July $31^{\text {st }} 2019$

\section{Introduction:}

Refrigerator has an important and regularly utilised thermal system for commercial and industrial purpose. It requires energy for the heat transfer processes in the thermal systems. Energy conservation is now facing with the challenge of applying the latest technology for facilities and improvement that can be justified on its own merit. It is very much essential to put more efforts for improving the efficiency of thermal systems in the era of green energy crises.Energy conservation is now facing with the challenge of applying the latest technology for facilities and improvement that can be justified on its own merit. Energy conservation is the technique to be adopted to face energy crisis under these circumstances. It is very much essential to put more efforts for improving the efficiency of thermal systems because of increasing energy prices and increasing concern of global warming. One of the methods of increasing efficiency is to recover and utilize waste heat from thermal systems for various applications like water heating [11]. Hot water is required for various applications like bathing, processing, cooking, dish washing, sterilization, and utensils cleaning in dairy. In such applications, water is heated by electrical heating or burning the fossil fuels which is costly and also increases global warming.

Use of waste heat recovery is an important technique of reducing total energy costs in energy system design [22]. If the heat recovery system is designed optimally and implemented in residential and small-scale commercial systems, the cumulative benefits would be significant. Waste heat before rejecting to the environment, we utilize a part of this energy in heating applications. Various waste heat sources are available such as domestic and urban waste which includes heat losses in cooking appliances, heat losses in air conditioners, heat losses in HVAC systems etc. [14]. Waste heat recovery system can be used in various applications but in present study, we shall focus on the use of waste heat recovery in air-cooled domestic refrigerator. Attachments need to be developed to recover waste heat energy and coefficient of performance increment in refrigeration systems by sub cooling technique in domestic refrigerator.

At many places, heating and cooling systems are simultaneously used. Air conditioning and refrigeration systems are designed to remove the heat from interior spaces and reject it to the ambient air. Heat rejection may occur directly to the ambient, as in the case of most conventional air-cooled condenser, or to 
water, circulating from a cooling tower in case of water cooled condenser. The circulating water eventually rejects the heat to the ambient air, in the cooling tower. While this heat is of a "low-grade variety," it still represents wasted energy. From an energy conservation standpoint, it would be desirable to reclaim this heat in a usable form. The best and most obvious form of heat recovery is for heating water. This waste energy can be recovered and utilized for various applications, which not only saves the energy but also enhances the performance of system

Domestic refrigerators are major energy consuming appliances in household environment. A household refrigerator is a common household appliance that consists of a thermally insulated compartment and which when works, transfers heat from the inside of the compartment to its external environment so that the inside of the thermally insulated compartment is cooled to a temperature below the ambient temperature of the room. Heat rejection may occur directly to the air in the case of a conventional household refrigerator having air-cooled condenser.In most of the existing refrigeration system condensers are either air cooled /water cooled or appropriate type which create an operative constraint. To cater these problems if air-cooled condenser can be replaced with another type of condenser which is going to decrease the power input then the problem of energy consumption and higher electrical bill can be minimised.

An energy-based analysis which suits well between the classical thermodynamic approaches based on the first law and the energy approach based on the second law for the evaluation of a refrigeration system. The energy analysis of the modern refrigerator is a basic step to find out the amount of losses in each component of the vapour compression cycle. By using water cooled condenser, the heat recovery system will not change the basic refrigeration cycle. It will simply change the type of combination of condensers used to remove the heat from the refrigerator. Our aim is to optimize the power consumed by different parts of refrigeration cycle using water level condenser and reduce the heat losses in this cycle.

\section{Related Prior Research}

Use of waste heat recovery from thermal system is not a new technique altogether. The focus is placed on a need to develop effective, less costly and maintenance-free auxiliary integrated with main system to achieve waste heat recovery along with COP increment by varying expansion valves. If this idea is implemented at system design level, then there would be considerable saving of energy. For this research researcher conducts extensive bibliometric analysis of published academic articles and identifies the most influential research publications in the latest periods and their contribution in the heat recovery system in domestic refrigeration system. Following researchers contributed to the area of COP increment and waste heat recovery significantly.

Clark et al. [1] carried out experimentation on domestic refrigerator. They used water cooled condenser and regular air-cooled condenser in parallel. Following are the findings of this research: (i) rise in temperature of cooling water is $350^{\circ} \mathrm{C}$ in 100 hours of continuous operation, (ii) $18 \%$ - 20\% energy savings for hot water, and (iii) no deterioration of the refrigerant performance. Yilmaz [2] carried out experimentation on air condition unit. He used concentric tube type heat exchanger for heat recovery. He found that, when entering water temperature is less than ambient air temperature, efficiency of air conditioning unit is improved. Stinson et al. [3] conducted research in dairy refrigeration by recovering the heat from condenser. They found out that by using the watercooled condenser COP of the system is enhanced by $10 \%$ to $18 \%$. They also found that increase in condenser 
pressure reduces COP, and inclusion of heat recovery heat exchanger reduces head loss. Alex et al. [4] prepared an analytical model of a residential desuperheater. They found that the results of mathematical model and results of experimental setup vary within 12\%. Rane et al. [5] developed sensible heat recovery unit and carried out experiments. Waste heat recovered is utilized for water heating. Their findings are: (i) Chiller cooling capacity enhanced by $30 \%$ and COP by $20 \%$, (ii) fuel saving reported 81 liters HSD/day, annual savings of Rs. 10 Lac/year, (iii) Reduction in $\mathrm{CO}_{2}$ emissions 450 ton in 4 years, and (iv) simple payback of 3 to 6 months.

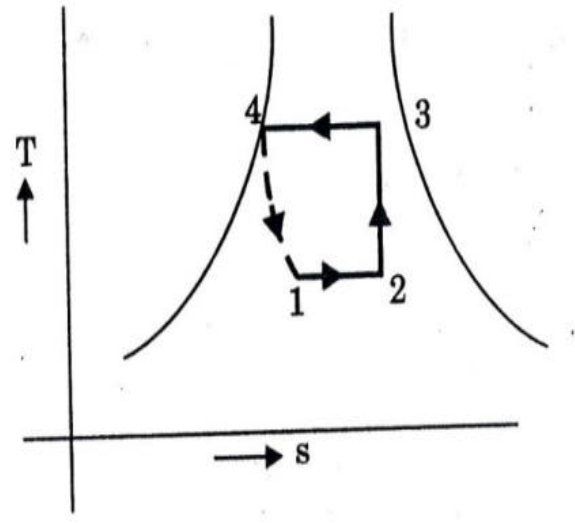

(a)

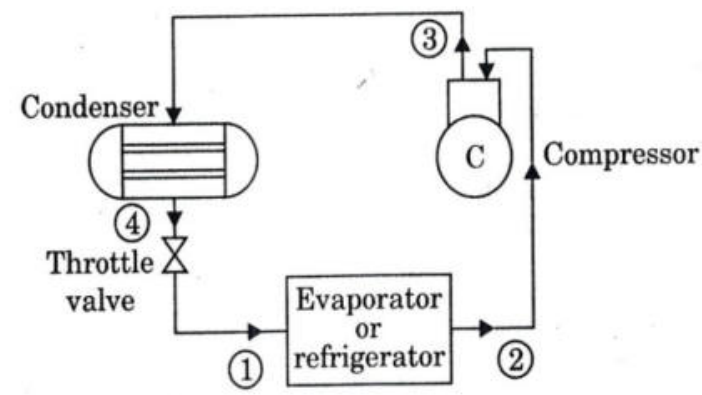

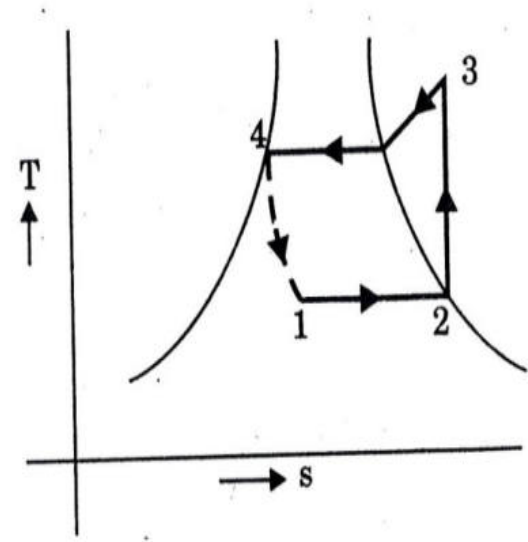

(b)

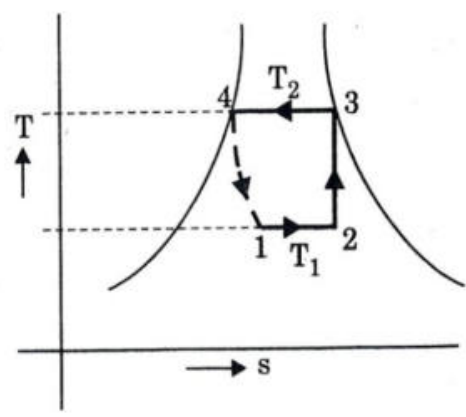

Fig. 1 Vapour Compression Refrigeration system with water cooled condenser in three cases a) Wet Condensation b) Superheated condensation c) Saturated Condensation

J. Khedari et al. [6] investigates the performance of a new hybrid domestic hot water system that combines solar energy with waste heat from a thermoelectric (TE) air-conditioner. To this end, 30 TE modules model no. TEC1-12704 (module specifications: $40 \times 40 \mathrm{~mm}$, maximum operating voltage and current: 13.5 VDC and 4.4 Amp) were used. The storage tank capacity was 120 liters. The volume of the testing room for 
cooling was $2.5 \mathrm{~m}^{3}$. Investigations were undertaken by varying the voltage to the thermoelectric module $(50$, 100 , and $150 \mathrm{VDC}$ ), water mass flow rate and air velocity passing through the TE heat exchangers: 10, 15 1/min and $2.5,5 \mathrm{~m} / \mathrm{s}$, respectively. It was found that this system can heat up the 120 litres to $50^{\circ} \mathrm{C}$ within 2 hours. The cooling capacity was $176 \mathrm{~W}$. After that, the cooling capacity decreased as a result of the increase of water temperature returned from the tank and circulated through TE water/solid heat exchanger. Finally, under design consideration used in this study, the optimum conditions for operating the hot water production and cooling as well are: $100 \mathrm{VDC}$, water flow rate of $15 \mathrm{l} / \mathrm{min}$ and air velocity at $2.5 \mathrm{~m} / \mathrm{s}$. The corresponding highest coefficient of performance of the hybrid system is about 3.12. Jie Ji et al.[7] the technology of using a heat pump for space conditioning and domestic hot water heating in residences has been developed for half a century. The earlier airto-water heat pumps and water-heating heat pumps suffered from drawbacks like high costs, unreliable operation, and inflexible applications. They were not well positioned in the market to attract customers. This paper introduces a novel air conditioning product that can achieve the multi-functions with improved energy performance. The basic design principles and the laboratory test results are presented. The results showed that by incorporating a water heater in the outdoor unit of a split-type air-conditioner so that space cooling and water heating can take place simultaneously, the energy performance can be raised considerably. S. C. Walawade [8] for the protection of global environment and from the point of fuel consumption, energy saving is one of the key matters. So it is important that a effective effort should be made for conserving energy through waste heat recovery too. The main objective of this paper is to study "Waste Heat recovery system for domestic refrigerator". Author attempts to utilize the waste heat from condenser of refrigerator. In minimum constructional, maintenance and running cost, this system is much useful for domestic purpose. It is effective alternative method to improve the efficiency of domestic refrigerator and reuse the waste heat. The author finds it technically and economically feasible. Y. A Patil \& H .M. Dange [9] refrigerator has become an essential commodity rather than luxury item. The heat absorbed in refrigerated space and the compressor work added to refrigerant is too rejected to ambient through a condenser. The heat recovery from the household refrigerator is by thermo siphon. From the experimentation it was found that after recovering heat from the condenser of the domestic refrigerator its energy consumption get reduced than conventional refrigerator. The maximum temperature achieved in water tank with 100 litre of water is $45^{\circ} \mathrm{C}$ at the full load condition. If the water tank contains 50 litres of water then it gets heated to $45^{\circ} \mathrm{C}$ in just 5 to $6 \mathrm{hrs}$. After that performance of the system gets decreased. So it needs regular use of that hot water. Thakre S. H. [10] Waste heat recovery is the process of capturing waste heat (thermal) energy for beneficial purposes. Energy savings and efficiency improvements of energy systems are important tasks on the path towards a more sustainable future. Conventional power stations convert only about $33 \%$ of their input heat to electricity. The remaining $67 \%$ emerges from the turbines as lowgrade waste heat with no significant local uses so it is usually rejected to the environment. The present work is based on these low conversion efficiencies, strongly suggesting to find productive uses for this waste heat.

N. B. Chaudhari [11] Heat recovery set up from condenser of a refrigerator was developed using thermo siphon system. It eliminates the need of circulating pump. Theoretical COP without heat recovery is about 1.88 and with heat recovery system it is 2.53 . The actual COP of air-cooled condenser system is 1.078 and for water cooled with heat recovery system practically COP is 3.79. Sukani Sunny et. al.[12] proposed the thermo electrical module of refrigeration system to increase the efficiency of the system in terms of refrigerating 
capacity. Lakshya Soni [13] the heat recovery technique of refrigeration system provides a compound air-cooling and water-cooling. By using this system result shows improvement in COP and reduction in power consumption. The temperature difference obtained between the water inlet and outlet exceeds more than $10^{0} \mathrm{C}$. The hot air by this system gives the temperature up to $46^{\circ}$ C. D.S. Kim et. al.[14] A comparison is made by authors between the different solutions both from the point of view of energy efficiency and economic feasibility. Solar electric and thermo-mechanical systems appear to be more expensive than thermal absorption systems. Absorption and adsorption are comparable in terms of performance but adsorption chillers are more expensive and bulkier than absorption chillers. Vivek Sahu et. al.[15] presents the experimental and theoretical analysis of domestic refrigeration system by using wire-on-tube condenser with different spacing of wire, operating parameters like heat transfer rate, condenser pressure and condenser temperature. Refrigerating effect is increased by using wire-on-tube condenser comparatively power consumption remains same as with air-cooled condenser in a domestic refrigeration system.

Rahul Patel et.al.[16] In this paper performance COP, refrigeration capacity, condensation effect and compressor work done of domestic refrigerator is studied through an experimental set up where air-cooled condenser is replaced by water-cooled condenser. It is observed that in the case of water cooled condenser, there is drop-in condenser pressure as well as evaporator pressure relative to air cooled condenser. In case of water cooled condenser, power consumption of compressor decreases relative to the air-cooled condenser. Romdhane Ben Slama [17] the quantity of heat released on the level of the condenser is 3 to 4 times the electric power consumed by the compressor, and even with an operation discontinuous of the compressor (presence of thermostat), this energy is equivalent the useful energy delivered by two $\mathrm{m}^{2}$ of solar collectors, which generally receives the solar water heaters installed. Therefore the coupling of the refrigerator to the water-heater can be only one success in the heating of water and the rise in its temperature to an acceptable threshold. Sagar Patil [18] develops hybrid refrigerator by introducing two Peltier modules (thermoelectric) in domestic refrigerator and to analyse compressor cycles of conventional refrigerator with thermoelectric to increase energy efficiency of vapour compression cycle. It is observed that by introducing thermoelectric effect, energy consumption of VCR is reduced by almost $10.92 \%$ annually, which accounts for 80 units per year. Sreejith.K [19] the objective of this paper was to study the performance of household refrigerator having both air and water-cooled condenser, with $0.06 \%$ mass fraction $\mathrm{CuO}$ nanoparticle-lubricant mixture and different types of compressor oils. The experiment was done using $\mathrm{HFC134a}$ as the refrigerant, $\mathrm{CuO}$ nanoparticle, Polyol-ester oil (POE) oil which is used as the conventional lubricant in the household refrigerator and SUNISO 3GS mineral oil as the lubricant alternatively. The result indicates that the refrigerator performance had improved while using $\mathrm{CuO}$ nanoparticlelubricant mixture. Sreejith K [20] the objective of this paper was to investigate experimentally the effect of different types of compressor oil in a domestic refrigerator having water cooled condenser. The experiment was done using HFC134a as the refrigerant, Polyol-ester oil (POE) oil which is used as the conventional lubricant in the domestic refrigerator and SUNISO 3GS mineral oil as the lubricant alternatively. The performance of the domestic refrigerator and HFC134a/POE oil system was compared with HFC134a/SUNISO 3GS mineral oil system for different load conditions. The result indicates that the refrigerator performance had improved when HFC134a/SUNISO 3GS mineral oil system was used instead of HFC134a/POE oil system on all load conditions. 
of refrigeration system on different load condition compare to the air-cooled condenser. The results showing that the COP is greater when the system is working with coolant cooled condenser and work done by compressor is also reduced by coolant cooled condenser, thus the energy consumption can be reduced. The results indicate that the refrigerator performance had improved when coolant-cooled condenser was used instead of air-cooled condenser on all load conditions. Sneha Y. Naukarkar et.al.[22] the main objective of this experimental investigation is to enhance the heat rejection rate of the condenser by incorporating axial fan with maximum speed of $4.6 \mathrm{~m} / \mathrm{s}$ at the bottom of condenser tube and the performance is analysed by natural and forced convection condenser under varying mass flow rate of air and refrigerant (R134a). Results of experimentation revealed that Heat rejection rate of forced convection condenser increased by $36.5 \%$ and COP is improved up to 33.43\%. Sanjana V. Bharambe et.al.[23] this paper consists of exergy analysis of this domestic refrigerator, working on eco-friendly refrigerant R-600a, to check for exergy destruction in the components. Exergy is the amount of available energy. Exergy destruction thus gives for maximum amount of un-utilized energy in the system. The aim of the present work is to improve the performance and efficiency of the domestic refrigerator by a change in condenser by exergy analysis of the systems. Vinayak Nathjogi et.al.[24] the main objectives of their research work are is to extract the heat from the domestic refrigerator by designing a compact condenser. Recover the heat in minimum possible time and increase the COP and overall efficiency of the system. Power consumption or LPG consumption can be eliminated for water heating. Hot water can be used for geysers, laundry, and dishwashing like applications. Nishikant Z. et.al.[27] In this paper, experimental study performance of water cooled condenser is compared with the air-cooled condenser in a domestic refrigeration system. To perform the experiment $165 \mathrm{~L}$ refrigerator is selected which is designed to work with R-134a. The result shows that the COP of air-cooled condenser is between the range 2-2.5 and the COP of water cooled condenser is between the ranges 3.6 - 4. Thus the conclusion is made that the COP of the water-cooled condenser is higher than air-cooled because of the lower pressure difference between evaporator $\&$ condenser at 40 -watt condition. G.G. Momin et. al.[28] aim of the paper is to recover waste heat from condenser unit of a household refrigerator to improve the performance of the system. The heat recovery from the household refrigerator is by thermo siphon. From the experimentation it was found that after recovering heat from the condenser of the domestic refrigerator its power consumption get reduced than conventional refrigerator. A summary of research work done by different researchers shown in the table no. 1 with the name of researcher and technologies used by them to analyse the work 
Table No. 1:--Description of Related Research

\begin{tabular}{|c|c|c|c|}
\hline Sr.No & Name of Researcher & Technology & Outcome \\
\hline 1 & $\begin{array}{l}\text { Romdhane Ben } \\
\text { Slama (2009) }\end{array}$ & Use of two heat exchangers & Total COP of system increases up to 7 \\
\hline 2 & Sreejith K.(2013) & $\begin{array}{l}\text { Investigate experimentally the effect of } \\
\text { different types of compressor oil in a domestic } \\
\text { refrigerator having water cooled condenser }\end{array}$ & $\begin{array}{l}\text { Refrigerator performance had improved } \\
\text { when HFC134a/SUNISO 3GS mineral oil } \\
\text { system was used instead of } \\
\text { HFC134a/POE oil system on all load } \\
\text { conditions. }\end{array}$ \\
\hline 3 & $\begin{array}{l}\text { N.B.Chaudhari } \\
(2015)\end{array}$ & $\begin{array}{l}\text { Heat recovery from condenser of a } \\
\text { refrigerator by thermo-siphon system using } \\
\text { experimental setup }\end{array}$ & $\begin{array}{l}\text { COP increases by } 71 \% \text {, Heat recovered as } \\
410 \text { watt as compared to } 210 \text { watt. }\end{array}$ \\
\hline 4 & $\begin{array}{l}\text { Rahul Patel et al } \\
(2015)\end{array}$ & $\begin{array}{l}\text { In an experimental set up, the design of } \\
\text { condenser is of open tray type in which a net } \\
\text { of the cooling coil with equidistant extra fins } \\
\text { is fitted. }\end{array}$ & $\begin{array}{l}\text { Compressor work reduced to } 100 \text { psi from } \\
220 \text { psi. }\end{array}$ \\
\hline 5 & $\begin{array}{l}\text { Sagar Patil et al } \\
(2015)\end{array}$ & $\begin{array}{l}\text { Use of hybrid refrigerator combines } \\
\text { thermoelectric (Peltier) modules and VCR } \\
\text { cycle }\end{array}$ & $\begin{array}{l}\text { Reduction of energy increased up to } 10 \% \text {, } \\
\text { run time of compressor is reduced. }\end{array}$ \\
\hline 6 & $\begin{array}{l}\text { Akshay Gurav } \\
\text { et.al.(2016) }\end{array}$ & $\begin{array}{l}\text { Experimental study of effect of evaporative } \\
\text { condenser on the COP of domestic } \\
\text { refrigerator. }\end{array}$ & $\begin{array}{l}\text { COP is increased but energy consumption } \\
\text { is also increased }\end{array}$ \\
\hline 7 & $\begin{array}{l}\text { Lakshya Soni et.al. } \\
(2016) \text {, } \\
\text { Vinayak Nathjogi, } \\
\text { et.al.(2016) }\end{array}$ & $\begin{array}{l}\text { Heat recovery from condenser of a } \\
\text { refrigerator by using sub cooling experimental } \\
\text { setup }\end{array}$ & $\begin{array}{l}\text { COP increases up to } 5.5 \text { and temp. of } \\
\text { water increases up to } 46^{\circ} \mathrm{c} \text {. }\end{array}$ \\
\hline 8 & $\begin{array}{l}\text { Ahana Dweepan } \\
\text { et.al.(2016) }\end{array}$ & $\begin{array}{l}\text { Coolant cooled condenser is retrofitted with } \\
\text { household refrigerator. Coolant used in the } \\
\text { condenser is polyalkaline glycol. }\end{array}$ & $\begin{array}{l}\text { COP is increased. Workdone and energy } \\
\text { consumption is reduced }\end{array}$ \\
\hline 9 & $\begin{array}{l}\text { Sneha } \\
\text { Naukarkar } \\
\text { al.(2016) }\end{array}$ & $\begin{array}{l}\text { Experimental analysis and mathematical } \\
\text { modeling is to enhance the heat rejection rate } \\
\text { of the air cooled condenser by incorporating } \\
\text { axial fan with maximum speed of } 4.6 \mathrm{~m} / \mathrm{s} \text { at } \\
\text { the bottom of condenser tube }\end{array}$ & $\begin{array}{l}\text { Heat rejection rate of forced convection } \\
\text { condenser increased by } 36.5 \% \text { and COP is } \\
\text { improved up to } 33.43 \% \text {. }\end{array}$ \\
\hline 10 & $\begin{array}{l}\text { Sanjana } \\
\text { Bharambe } \\
\text { et.al.(2017) }\end{array}$ & $\begin{array}{l}\text { Improvement in the performance and } \\
\text { efficiency of the domestic refrigerator by a } \\
\text { change in condenser by exergy analysis of the } \\
\text { systems. }\end{array}$ & $\begin{array}{l}\text { Exergy analysis of the modern refrigerator } \\
\text { gives maximum exergy destruction of } \\
41.2 \% \\
\text { in the compressor followed by } 28.14 \% \text { in } \\
\text { the condenser. }\end{array}$ \\
\hline
\end{tabular}

\section{Conclusion}

It is found from the literature review that most of the research carried out is for recovery and utilization of partial 
superheat from the condenser, which is further used for various applications. By the result of literature review here we identify the research problem that many researchers' tries to use of water cooled condenser in domestic refrigeration system to increase the COP of system. But no one has proposed the commercial domestic refrigerator with utilization of optimum power. The power utilization can be done through the mathematical modelling of vapour compression system with water cooled condenser.

\section{Reference}

[1] Robert A. Clark, Richard N. Smith, and Michael K. Jensen, "Anexperimental study of waste heat Recovery From a residentialrefrigerator", 0-7803-3547-3-711, 1996 IEEE

[2]Dr.Emin Yilmaz, "Air conditioning waste heat to domestic hot water -a study design report”, Proceedings of IMECE 2007, ASMEInternational Mechanical Engineering Congress and Exposition,November 10-15, Seattle, Washington, USA

[3] G. E. Stinson, C. J. Stuman, D. J. Warburton, “ A dairy refrigerationheat recovery unit and its effects on refrigeration operation”, Journal of Agriculture Engineering Res. 36, pp 275-285, 1987

[4] Alex H. W. Lee and J. W. Jones, “Analytical model of a residential de-superheater”, Applied Energy, Vol. 57, No. 4, pp271-185, 1997.

[5] Milind V. Rane, Madhukar S. Tandale, "Benefits of superheat recoveryon chillers case study for a hotel installation", International Congress ofRefrigeration 2003, Washington, D.C

[6] J. Khedari, S. Maneewan, N. Pratinthong, W. Chimchavee\&Dr. J.Hirunlabh, "Domestic hot water system combining solar and wasteheat from thermoelectric air-conditioner", International Journal of Ambient Energy, Vol. 22, Issue 1,2001.

[7] Jie Ji, Tin-tai Chow, Gang Pei, Jun Dong, Wei He, "Domestic airconditionerand integrated water heater for subtropical climate”,Applied Thermal Engineering Vol. 23, pp. 581-592, 2003.

[8] S. C. Walawade, B. R. Barve, P. R. Kulkarni, "Design and development of waste heat recovery system for domestic refrigerator”, IOSRJournal of Mechanical and Civil Engineering, pp 28-32, 2012.

[9] Y. A. Patil1, H. M. Dange2, "Improving the performance of household refrigerator by recovering heat from the condenser", InternationalJournal of Science and Research, Vol. 2 Issue 6, June 2013

[10] S.V. Diwan, Sagar H. Thakre, T. Chethan Kumar, "Waste heatrecovery-technology and opportunities in fuel oil area of a thermalpower plant”, Dissertation report of M. Tech in Thermal Engineering,VeermataJijabai Technological Institute, Mumbai, 2011.

[11]N. B. Chaudhari, P. N. Chaudhari, "Heat recovery system from the condenser of a refrigerator - an experimental analysis", International Journal on Theoretical and Applied Research in Mechanical Engineering, ISSN (Print): 2319-3182, Vol. 4, Issue 2, pp 41-44, 2015.

[12] Sukani Sunny, SavajJayesh, "To improve COP of domestic refrigerator with the help of water cooling condenser”, International Journal of Innovative Research in Science,Engineering and Technology, Vol. 4, Issue 3, pp. 1229-1236, March 2015.

[13]Lakshya Soni, Pawan Kumar, Rahul Goyal, "Waste heat recovery system from domestic refrigerator for water and air heating”, International journal of Engineering sciences and research technology, Vol. 5, Issue 7, pp. 700-705, July 2016. 
[14]D.S. Kim,C.A. Infante Ferreira, "Solar refrigeration options - a state-of-the-art review”, International journal of refrigeration, Vol. 31, pp 3-15, 2008.

[15]Vivek Sahu, Pooja Tiwari, Abhishek Tiwari, "Performance analysis of domestic refrigrerator using wire-ontube condensor- a review”, International Journal of Current Research and Review, Vol. 04, Issue 16, pp.131-133, , Aug 2012.

[16] Rahul Patel, Ramji Tripathi, Sukhdev Gangwar, "Performance evaluation of conventional domestic refrigerator retrofitted with water cooled condenser", International Journal of Recent Scientific Research, Vol. 6, Issue, 6, pp.4495-4504, pp. 4495-4504, , June- 2015.

[17]Romdhane Ben Slama, "Thermodynamic heat water by the condenser of refrigerator", International Symposium on Convective Heat and Mass Transfer in Sustainable Energy April 26 - May 1, 2009, Tunisia.

[18] Sagar Patil, Kiran Devade, "Energy savings in domestic refrigerator using two thermoelectric modules and water cooling of condenser", International Journal of Innovations in Engineering Research and Technology, Vol. 2, Issue 7, pp 1-9, July-2015, Novateur Publications.

[19] Sreejith.K, "Performance evaluation of a household refrigerator using cuo nanoparticle lubricant mixture and various other compressor oils with different condenser modes", International Journal of Engineering Research and Development, Vol. 5, Issue 7, PP. 10-15, Jan.2013.

[20]Sreejith K., "Experimental investigation of a domestic refrigerator having water-cooled condenser using various compressor oils", Research Inventy: International Journal of Engineering and Science, Vol. 2, Issue 5, pp. 27-30, Feb. 2013.

[21]Ahana Dweepan, Akshay Raj, Jerin C Jhonson, Jebin S Simon, Sharath A R"Experimental investigation on refrigerator using air cooled condenser and coolant cooled condenser", International Journal of Mechanical and Industrial Technology, Vol. 4, Issue 1, pp. 25-30, April 2016 - Sept.2016.

[22] Sneha Y. Naukarkar, Dr M.M. Gupta, Shruti S. Chouhan, Yogesh V. Borse, "Experimental analysis and mathematical model of air cooled condenser in domestic refrigerator", International Advanced Research Journal in Science, Engineering and Technology Vol. 3, Issue 6, pp.103-107, June 2016.

[23]Sanjana V. Bharambe, Susmit A. Mulay, Suyash Jadhav, "Design and analysis of water cooled condenser", SSRG International Journal of Mechanical Engineering (SSRG-IJME) - Vol. 4 Issue 6, pp.1-5, June 2017.

[24]Vinayak Nathjogi, Shruti Suryawanshi, Abhijit Khude, Dilbar Sayyad, S.B.Teli, "Design of compact condenser for waste heat recovery and COP enhancement of refrigerator", International Journal for Scientific Research \& Development| Vol. 4, Issue 04, pp. 65-69,2016.

[25]Anshul Sarin, Aatish Goel, Tushar Sharma, Abhishek Misra, ShivamTyagi, "Effective utilization of condenser heat of a refrigerator in a heating chamber", International Journal of Scientific and Research Publications, Vol. 7, Issue 12, pp. 170-173, December 2017.

[26]Akshay Gurav, PragatiKainge, GanpatlalKhandelwal, Shrinivas Deshmukh, D.B.Nalawade, "Experimental study of effect of evaporative condenser in domestic refrigerator", International Journal of Research in Advance Technology, Sp. Issue, NCMMM-2016, 19 March-2016.

[27] Nishikant Z. Adkane, Saroj V. Borkar, Ramesh D. Bokde, "Comparative analysis of domestic refrigerator by using water cooled condenser with air cooled condenser", International Research Journal of Engineering and Technology, Vol. 4, Issue 06, June -2017. 
[28]G.G. Momin, S.R.Deshmukh, M.T. Deshmukh, P.T.Chavan, P.P.Choudhari, “COP enhancement of domestic refrigerator by recovering heat from the condenser", International Journal of Research in Advent Technology, Vol.2, No.5, pp.402-406, May 2014.

[29]Anil S Katarkar, Lenin Dhale, "Coefficient of performance increment indomestic refrigerator: a literature review", International Journal of Engineering Research and Technology, Vol. 3 Issue 4, pp. 768-772, April 2014. 